\title{
Influence of weathering on visual and surface aspect of wood plastic composites: Correlation approach with mechanical properties and microstructure
}

\author{
Célia Badji, Lata Soccalingame, Hélène Garay, Anne Bergeret*, Jean-Charles Bénézet \\ Ecole des Mines d'Alès, C2MA, 6 avenue de Clavières, 30319 Alès Cedex, France
}

\section{A B S T R A C T}

This study aims to assess and understand simultaneously the changes in visual aspect, surface topography and mechanical properties of a wood flour reinforced polypropylene (PP) composite under natural and artificial weathering conditions. Compounds were produced through twin-screw extrusion followed by injection molding in order to obtain dog bone samples. A one-year natural outdoor exposure and a xenon-arc accelerated weathering were studied. As expected, mechanical performances are decreased under UV exposure. This performance degradation goes along with important changes in visual aspect. In addition to commonly used microscopy observations, other methods such as colorimetry, spectrogoniometry and confocal rugosimetry are used to characterize the surface aspect through color, gloss and roughness properties. These analyses revealed that ageing induces a surface bleaching, a wood particle protrusion and numerous micro-cracks. Moreover the chain scission attested by Size Exclusion Chromatography (SEC) and lixiviation on the surface induces roughness and gloss loss. Otherwise biocomposites were more degraded under natural weathering. This paper gives new insights in understanding how weathering affects physico-mechanical properties of wood plastic composites (WPC). For that, the Principal Component Analysis (PCA) gives global overview about effects of type of weathering and wood rate on physical, mechanical and chemical properties by calculating their contributions to the drawing of axes (Principal Components) during PCA.

Keywords:

Wood flour

Weathering

Color

Roughness

Mechanical properties

Principal Component Analysis

\section{Introduction}

Wood plastic composites (WPC) are spreading all around the world and are mainly used in construction applications (decking, fencing ...). Indeed the total production of WPC in Europe was of 305000 metric tons (MT) in 2012 and is expected to rise to 780000 MT or even 1250000 MT in 2020 [1]. The widest used matrices are polyethylene (PE), polyvinyl chloride (PVC) and polypropylene (PP). Otherwise, the success of wood-based materials can be explained by their aesthetic appeal [2].

However, the hydrophilic character and solar radiation sensibility of wood flour limit the WPC durability under outdoor exposition [3]. Indeed cellulose and hemicelluloses contained in vegetable fibers and flours absorb water and cause swelling of composites under high humidity rate or rain.

\footnotetext{
* Corresponding author.

E-mail address: Anne.Bergeret@mines-ales.fr (A. Bergeret).
}

Many studies investigated on the accelerated weathering of WPC. They examined the influence of the time of exposure on the mechanical properties, the chemical composition and the visual properties [3-8]. All researchers agreed that oxidation reactions due to high temperatures or UV radiation, particles swelling with high humidity in the environment and weak adhesion between polymer and fibers were the main causes of alteration of mechanical and visual properties. In fact UV radiation induces photo-oxidation especially of lignin, which is the more sensitive to UV light component present in flours because of presence of chromophoric groups in its structure [4] linked to the surface bleaching. Two reactions may occur. Firstly a chain scission of lignin macromolecules can lead to the formation of paraquinonic structures causing a yellowing of WPC. Then paraquinones can reduce to hydroquinones which give a white color to the composites (photo-bleaching). This discoloration of WPC from brown to chalky white has been observed for wood flour polypropylene composites by Peng et al. [4]. The comparison between WPC and pure lignin reinforced polypropylene composites showed that 
the discoloration was more pronounced for the last composite and confirms that lignin is more sensitive to UV weathering. Another composite pure cellulose/PP was tested and the bleaching of this composite was slower: the material was more stable. Also, due to the sensitivity of lignin face to environmental conditions, WPC sometimes require the addition of color stabilizers [9-12].

Fewer studies investigated the effects of natural weathering on WPC. For example, Fabiyi et al. compared the effects of exterior and accelerated weathering on pine wood flour-high density polyethylene and polypropylene composites [13]. Infrared characterization revealed the formation of oxygenated molecules such as carbonyl groups, carboxylic acids and esters. It implied a surface oxidation of WPC. They also noted a bleaching of WPC by spectrocolorimetric analysis, suggesting that lignin has been degraded during the two types of weathering. Homkhiew et al. worked on the influence of plastic grades (virgin and recycled polypropylene), the influence of the loading of wood flour and the addition of UV stabilizers on the discoloration after natural exposition [14]. As well as for Fabiyi's studies, a color fading of the composite was observed and increased with the wood content even if stabilizers retarded a little the rate of discoloration. Butylina et al. noted two stages of surface lightness reduction after the bleaching of WPC during an exterior weathering: the first was due to dusty deposits on the surface and the second was the result of the decrease of solar radiation in autumn [10].

The polymer matrix and wood flour are mainly deteriorated on composites surface during weathering which results in a reduction of the molecular weight of the polymer [5] and an evolution of surface roughness [6], [15]. Peng et al. measured the surface roughness of WPC before and after accelerated weathering by AFM analysis [6]. They noted an increase of the roughness parameter due to the degradation of polypropylene and wood loss on weathered surfaces. According to Muasher and Shain, the photo-degradation mechanism of the polymer occurs via Norrish type I and results in formation of free radicals [12]. These highly reactive molecules affect the polymer and lead to termination via crosslinking or polymer chain scission. Then the roughness caused either by the formation of cracks after photo-oxidation $[8,16]$, or a wood particles loss or finally a decrease in the interfacial bonding between the wood flour and the polymer matrix [17] induce a loss of gloss for the biocomposites.

Even if lots of studies investigated the evolution of color of WPC during weathering, just a few ones dealt with the gloss and roughness thanks to spectral measurements. Until today, the techniques used to evaluate the surface state of WPC are based on atomic and electronic microscopic measurements (AFM, SEM). Although they present high resolution, these characterization methods sometimes imply sample destruction or damage and results can be dependent on measurement conditions (for instance, heights measured during the AFM analysis can be dependent on the dot's type used and the analysis under air can interfere results). Here optical measurements will be used and involve spectral reflection measurements. The advantages of these rugosimeters are double. It consists in non-destructive measurements and shorter analysis times are required.

In regards to this state of the art, the novelty of this paper consists in a simultaneous analysis of visual aspect changes, surface topography and mechanical properties of a non-stabilized wood flour reinforced polypropylene (PP) composite under natural and artificial weathering conditions. Firstly, the weathering influence on WPC is studied by every characteristic assessment one by one. Then, a Principal Component Analysis (PCA) approach clearly shows which properties gather or differentiate samples and the links between these properties.

\section{Materials and methods}

\subsection{Materials}

Polypropylene (PP) used in this study is a standard homopolymer PP H733-07 grade supplied by Braskem Co. (Brazil) with a melt flow rate of $7.5 \mathrm{~g} / 10 \mathrm{~min}\left(230{ }^{\circ} \mathrm{C}, 2.16 \mathrm{~kg}\right)$ according to ISO 1133 standard. Maleic anhydride grafted polypropylene (MAPP) with a $1 \% \mathrm{w} / \mathrm{w}$ grafting rate is used as coupling agent and provided by Arkema Co. (France) under the trademark Orevac ${ }^{\circledR}$ CA100. It was dry-mixed before processing at $3 \% \mathrm{w} / \mathrm{w}$ of the PP. The wood flour is based on spruce wood with a particle size included in the $200 \mu \mathrm{m}-500 \mu \mathrm{m}$ range and was purchased from AFT Plasturgie Co. (France). The wood flour was added at $10 \% \mathrm{w} / \mathrm{w}$ and $30 \% \mathrm{w} / \mathrm{w}$ in the matrix.

Table 1 sums up the designations of the different studied materials:

\subsection{Material processing}

The PP matrix and the wood particles are mixed together in a BC21 Clextral (France) co-rotating twin-screw extruder. Its L/d ratio is 36 with a $25 \mathrm{~mm}$ screw diameter and a $900 \mathrm{~mm}$ screw length. Temperature is set at $180{ }^{\circ} \mathrm{C}$ along the barrel. The screw speed is fixed at $300 \mathrm{rpm}$ with a total feeding rate of $4 \mathrm{~kg} \mathrm{~h}^{-1}$. The extruder is equipped with a $4 \mathrm{~mm}$ die diameter. The extruded compound rods are cooled into water and granulated. Pellets are kept $6 \mathrm{~h}$ at $80^{\circ} \mathrm{C}$ in an air-pulsing dryer.

The pellets are injection molded to produce dog-bone ISO $1 \mathrm{~A}$ samples on a Krauss-Maffei KM50-T180CX. The temperature is fixed at $210^{\circ} \mathrm{C}$ along the barrel. The mold is kept at $30^{\circ} \mathrm{C}$ by a water cooling system. The plasticization and injection speeds are set respectively at $120 \mathrm{rpm}$ and $60 \mathrm{~cm}^{3} \mathrm{~s}^{-1}$.

\subsection{Weathering conditions}

\subsubsection{Natural weathering}

Concerning the natural weathering, ISO 1A samples are exposed according to EN ISO 877 standard in an outdoor natural site in Alès (South of France) on galvanized steel racks as shown on Fig. 1. The exposure included climatic conditions from the four annual seasons (June to June) allowing to consider the contribution of each season and verify long-term degradation effects. According to the mentioned standard, the samples are fixed on the racks at an angle of $45^{\circ}$ with the ground on a flat land and directed toward the South.

\subsubsection{Accelerated weathering}

Concerning the artificial accelerated weathering, ISO 1A samples are exposed according to EN ISO 4892-2 standard in a xenon arc chamber Weather-Ometer (WOM) from Atlas Co. with a $3500 \mathrm{~W}$ lamp. The artificial ageing tests were performed by PEP institution (Pôle Européen de Plasturgie, Bellignat, France). The lamp characteristics report an irradiance of $60 \mathrm{~W} / \mathrm{m}^{2}$ in the range of $300 \mathrm{~nm}-400 \mathrm{~nm}$ (UV radiations). A 120-min cycle was applied and repeated 168 times for total exposure duration of 14 days. This cycle is composed of two stages: a 102-min of UV exposure at $60{ }^{\circ} \mathrm{C}$ and

Table 1

Designations of materials.

\begin{tabular}{llll}
\hline & PP $(w t \%)$ & Wood flour $(w t \%)$ & MAPP $(w t \%)$ \\
\hline PP & 100 & 0 & 0 \\
PP10 & 87.3 & 10 & 2.7 \\
PP30 & 67.9 & 30 & 2.1 \\
\hline
\end{tabular}




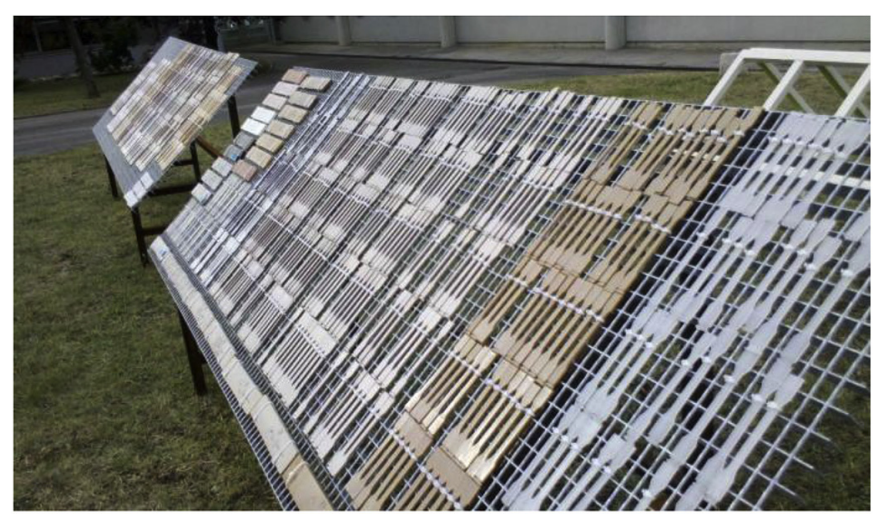

Fig. 1. Exposure racks used in this study.

$65 \pm 5 \% \mathrm{HR}$ followed by an 18 -min water spraying. Considering UV radiation only, this duration corresponds to three months of natural weathering, stage during which WPC physical properties vary the most [8]. Calculations are explained in a previous work [5]. That is why this artificial and one-year natural weathering cannot be compared. Otherwise, PP10 is not studied for the artificial weathering. Table 2 sums up the designations of the different weathered states.

\subsection{Mechanical characterization}

Tensile tests are carried out at $23{ }^{\circ} \mathrm{C} \pm 2{ }^{\circ} \mathrm{C}$ and $50 \% \pm 10 \% \mathrm{HR}$ according to the ISO 527 standard. A Zwick ${ }^{\circledR} 1455$ model apparatus is used with a $20 \mathrm{kN}$ load cell and a Clip-On extensometer for displacement measurements during modulus tests. The crosshead speed is set at $1 \mathrm{~mm} / \mathrm{min}$ for the tensile modulus measurements, $50 \mathrm{~mm} / \mathrm{min}$ for the break property measurements. Five measurements are carried out for modulus measurements (E) and for strength (RM) and elongation (ER) at break measurements.

\subsection{Visual property measurements}

\subsubsection{Spectrocolorimeter}

The color analysis of non-weathered and weathered samples was performed with a Chroma Sensor 3 spectrocolorimeter. The configuration illuminant/observer (viewing angle) chosen was $\mathrm{D} 65 / 10^{\circ}$. The color was determined according to the CIE $1976 L^{*}, a^{*}$, $b^{*}$ system. The $\mathrm{L}^{*} \mathrm{a}^{*} \mathrm{~b}^{*}$ system is perceptual and its construction allows to calculate color differences as it is a uniform system. The coordinates $\mathrm{L}^{*}, \mathrm{a}^{*}$ and $\mathrm{b}^{*}$ obtained from the reflectance curves report the lightness and the chromaticity: an increase of $\mathrm{L}^{*}$ (from 0 to 100 ) signifies a lightening material. $\mathrm{a}^{*}$ and $\mathrm{b}^{*}$ are the chromaticity positions on axes from -300 to +300 which are respectively green to red and blue to yellow axes. $\Delta \mathrm{L}^{*}=\mathrm{L}^{*}{ }_{2}-\mathrm{L}^{*}{ }_{1}, \Delta \mathrm{a}^{*}=\mathrm{a}^{*}{ }_{2}-$ $\mathrm{a}^{*}{ }_{1}$ and $\Delta \mathrm{b}^{*}=\mathrm{b}^{*}{ }_{2}-\mathrm{b}^{*}{ }_{1}$ with $\mathrm{L}^{*}{ }_{2}, \mathrm{a}^{*}{ }_{2}$ and $\mathrm{b}^{*}{ }_{2}$ the coordinates of weathered samples and $\mathrm{L}^{*}{ }_{1}, \mathrm{a}^{*}{ }_{1}$ and $\mathrm{b}^{*}{ }_{1}$ the coordinates of nonweathered samples are calculated to evaluate the evolution between the initial and final states. Mean values were obtained from the analysis of six areas of three samples.

Table 2

Designations of the different states.

\begin{tabular}{llll}
\hline & Unweathered & Naturally weathered & $\begin{array}{l}\text { Artificially } \\
\text { Weathered }\end{array}$ \\
\hline Designation & $\begin{array}{l}\text { UWPP or UWPP10 } \\
\text { or UWPP30 }\end{array}$ & $\begin{array}{l}\text { NWPP or NWPP10 } \\
\text { or NWPP30 }\end{array}$ & $\begin{array}{l}\text { AWPP or } \\
\text { AWPP30 }\end{array}$ \\
\hline
\end{tabular}

\subsubsection{Spectrogoniometer}

This technique allows determining the angular distribution of the intensity of light reflected by the surface of a material. The distribution of the light depending on the angle of detection can be related to the surface state of the samples. Indeed the gloss $(G)$ of a material is more pronounced as the light is reflected directionally, meaning in one direction. On the contrary, a rough surface reflects the light in all directions. The intensity is thus not concentrated in one direction.

A GON 360 goniometer associated to a MAS 40 spectrometer with a halogen lamp and a power supply of $12 \mathrm{~V}$ was used. The source angle is arbitrarily fixed at $30^{\circ}$. Detector angles vary from $10^{\circ}$ to $-70^{\circ}$ with an angular step smaller in the specular zone to be able to detect the strong variations of intensity in this zone. The spectral range of analysis is $380-780 \mathrm{~nm}$. From every spectrum $\mathrm{I}=\mathrm{f}(\lambda(\mathrm{nm}))$ obtained for every detector angle, we can represent the total intensity versus the detector angle: $\mathrm{I}(\mathrm{u} . \mathrm{a})=\mathrm{f}\left(\Theta\left(^{\circ}\right)\right)$. Results were obtained from the analysis of three areas of three samples.

In order to easily evaluate correlations between gloss parameter and other properties thanks to Principal Component Analysis, the ratio between the maximal intensity obtained for the angle of detection of $30^{\circ} \mathrm{I}\left(30^{\circ}\right)$ and the intensity obtained for the angle of $32^{\circ} \mathrm{I}\left(30+2^{\circ}\right)$ is calculated for all samples (Eq. (1)). The higher $\mathrm{G}$ value is, the glossier the surface seems.

$G=\frac{I\left(30^{\circ}\right)}{I\left(30^{\circ}+2^{\circ}\right)}$

\subsection{Surface texture characterization}

\subsubsection{Environmental scanning electronic microscope}

Environmental scanning electron microscopy (ESEM) is performed using a Quanta FEG 200 set-up in order to analyze the microstructural organization of the surface degradation. Surfaces were carbon coated beforehand. Samples were observed on their ageing-exposed surface at $15 \mathrm{kV}$.

\subsubsection{Confocal rugosimeter}

A MICROMESURE STIL system equipped with a STIL CHR150 optical sensor was used to evaluate the roughness by altitude measurement of each surface point on the sample without contact with the sample according to the ISO 25178 international standard.

A white light source is imaged by an objective lens with extended axial chromatism on a series of monochromatic point images in the measurement space [18]. When the measured sample intercepts the measurement space at a specific point $\mathrm{M}$, a single of these monochromatic point images is focalized at M. Thanks to a pinhole located at the image of $\mathrm{M}$, only the wavelength $\lambda \mathrm{M}$ will pass through the spatial filter.

A $(\mathrm{X}, \mathrm{Y})$ scanning allows obtaining the image of a plane of the sample surface located at a precise distance from the objective. Acquisition software SurfaceMap allows the control of the station and the post-treatment MountainsMap ${ }^{\circledR}$ software is used to analyze the surface geometry and to calculate roughness parameters. The micrometric range of the optical pen was $300 \mu \mathrm{m}$, meaning that the distance between the lowest and the highest points of the surface cannot exceed $300 \mu \mathrm{m}$. It permits a tridimensional analysis. The analyzed area $X^{*} Y$ was $3 \mathrm{~mm} *$ $3 \mathrm{~mm}$ with an analysis step of $10 \mu \mathrm{m}$ for both directions. The tridimensional roughness parameter Sa followed for the samples is the arithmetic mean of the absolute of the height values (Eq. (2)): 


$$
\mathrm{Sa}=\frac{1}{N M} \sum_{x=0}^{N-1} \sum_{y=0}^{M-1}|z(x, y)|
$$

With $\mathrm{M}$ the number of points along the $\mathrm{X}$ axis, $\mathrm{N}$ the number of points along the $Y$ axis, and $z_{x, y}$ the altitude in $\mu \mathrm{m}$. Mean values and standard deviations were obtained from the analysis of three areas of three samples.

\subsection{Microstructure characterization}

\subsubsection{Size Exclusion Chromatography (SEC)}

Size-exclusion chromatography is performed in a high temperature gel permeation chromatograph to determine the evolution of the average molecular weights in weight and in number and the polydispersity index of PP. Fragments are cut in the injected samples and solubilized into 1,2,4- trichlorobenzene (Chromasolv, Sigma-Aldrich) at a concentration of $1 \mathrm{mg} \mathrm{mL}^{-1}$. The eluent was stabilized with $0.03 \mathrm{wt} \%$ of 2,6-di-tert-butyl-4-methylphenol (BHT, Fluka) to stabilize the polymer against oxidative degradation. These solutions are agitated during $15 \mathrm{~min}$ at $150{ }^{\circ} \mathrm{C}$ and, then filtered before test. The tests are carried out on a PL-GPC $220^{\circledR}$ from Agilent Technologies equipped with a guard column and two columns branded PLGel Olexis as well as a refractive index detector. The temperature was set at $135{ }^{\circ} \mathrm{C}$, and the flow rate was $1 \mathrm{mg} \mathrm{mL}$. The calibration curve was established from four Polystyrene Shodex narrow standards of respective molecular weights of $1,470,000$, $257,000,46,500$ and $7210 \mathrm{~g} \mathrm{~mol}^{-1}$. Results were then corrected using the so-called "universal calibration", based on the wellknown Mark-Houwink's relationship.

\subsubsection{Infrared spectroscopy}

Infrared spectroscopy is carried out to assess the evolution of chemical groups issued from the degradation phenomenon induced by weathering. A spectrometer IFS66 from Bruker ${ }^{\mathbb{B}}$ is used in ATR mode (Attenuated Total Reflectance). The spectra are measured from $400 \mathrm{~cm}^{-1}$ to $4000 \mathrm{~cm}^{-1}$ with a $2 \mathrm{~cm}^{-1}$ resolution. The mentioned peaks were normalized with the $2915 \mathrm{~cm}^{-1}$ attributed to a $\mathrm{C}-\mathrm{H}$ stretching band of methylene groups $\mathrm{CH}_{3}$. This band is chosen as a reference because it changed minimally during weathering.

\subsection{Principal Component Analysis (PCA)}

The PCA is carried out on Statistica 13 software. This statistical method consists in firstly representing individuals (here samples) living in a multidimensional space on a smaller subspace by projection of each sample on a plan with minimal loss of information of the dataset. The aim is to easily view similarities and differences thanks to their distance between each other and the dispersion of samples may highlight samples groups' formation. Two axes (two components) are represented by a proportion in \% which represents the inertia rate, i.e. the information rate, and reflects the quality of the representation.

Then the statistical analysis consists in a graphical representation of variables called correlation circle. For each variable, the correlation coefficient between the variable and the two components is calculated and this coefficient permits to draw the variable on the circle.

In the correlation circle, two variables are:

(i) positively correlated if they form an angle close to $0^{\circ}$,

(ii) not correlated if they form an angle of $90^{\circ}$,

(iii) negatively correlated if they form an angle close to $180^{\circ}$.
In order to transform the data onto unit scale (mean $=0$ and variance $=1$ ) and thus to compare easier the variables, the values of each variable for each individual are standardized by centering (mean subtracted to each variable) and reduction (each centered variable divided by the standard deviation).

\section{Results and discussion}

Firstly, the influence of the two types of weathering has been studied through the determination of mechanical, physical and chemical properties individually.

\subsection{Impact of weathering on the mechanical properties}

Tensile test curves are plotted in Fig. 2 for non-weathered, naturally and artificially weathered materials. At the initial state, PP has a ductile behavior with a high elongation at break of $130 \%$. The addition of wood flour leads to stiffer materials with low elongations whereas strengths were not improved. As expected, PP evolves from ductile to brittle behavior after UV exposure with a greater extent after natural weathering compared to artificial ageing. Little variations in curve shape can be observed for PP30 and PP10 between the different states. This difference of evolution between neat PP and composites was observed previously and was explained by a stabilizing role of lignin contained in wood flour $[3,4,6]$.

Table 3 lists the corresponding mechanical properties (Young's modulus (E), maximal strength (RM), and elongation at the maximal strength (ER)). After natural weathering, PP has a higher stiffness $(+13 \%$ ) compared to unaged PP but has lost almost $60 \%$ of its strength and about $85 \%$ of its standard elongation. This is due to PP crystallization induced by shorter macromolecular chains resulting from a polymer chain scission during UV weathering [19]. On the contrary PP10 and PP30 underwent both a decrease in stiffness $(-7 \%$ an $-16 \%$ respectively). A slighter drop in strength (about $-16 \%$ ) and elongation ( $-16 \%$ and $-10 \%$ respectively) was also observed. It can be assumed that would flour may hinder PP crystallization. Concerning artificial weathering, PP has a higher stiffness ( $+16 \%)$, the same strength and a lower elongation $(-46 \%)$ compared to the initial state. In comparison with the natural weathering, PP stiffness is slightly higher but is less degraded concerning the other tensile values. PP30 stiffness and strength are not impacted by the artificial ageing in contrast to the natural ageing but the elongation is lower ( $0.9 \%$ instead of $1.8 \%)$ than value for natural weathering. These results suggest that these artificial weathering conditions degrade much less mechanical properties than natural weathering. It is expected as these conditions simulate outdoor exposure for a duration ranging from 2 to 3 months [4].

\subsection{Impact of weathering on the visual appearance}

\subsubsection{Color}

The variations of $\mathrm{L}^{*}, \mathrm{a}^{*}$ and $\mathrm{b}^{*}$ parameters of neat PP and biocomposites after natural and artificial weathering compared to unaged samples are shown in Table 4.

Biocomposites experienced more $\mathrm{L}^{*}, \mathrm{a}^{*}$ and $\mathrm{b}^{*}$ variations than $\mathrm{PP}$ one during the two types of weathering. For each coordinate, the variation is lower than 1 for PP whereas for PP10 and PP30, these variations are always higher than 2 and can reach 25 . As concerns $\Delta \mathrm{L}^{*}$, an increase is observed for WPC which becomes more intense as the wood content increases. This indicates that the wood flour is mainly responsible of the sensibility of composites under ageing conditions. This bleaching is due to the photo-degradation of wood flour, and more precisely of the lignin whose chromophoric groups can absorb UV rays and form free radical groups. This photo- 

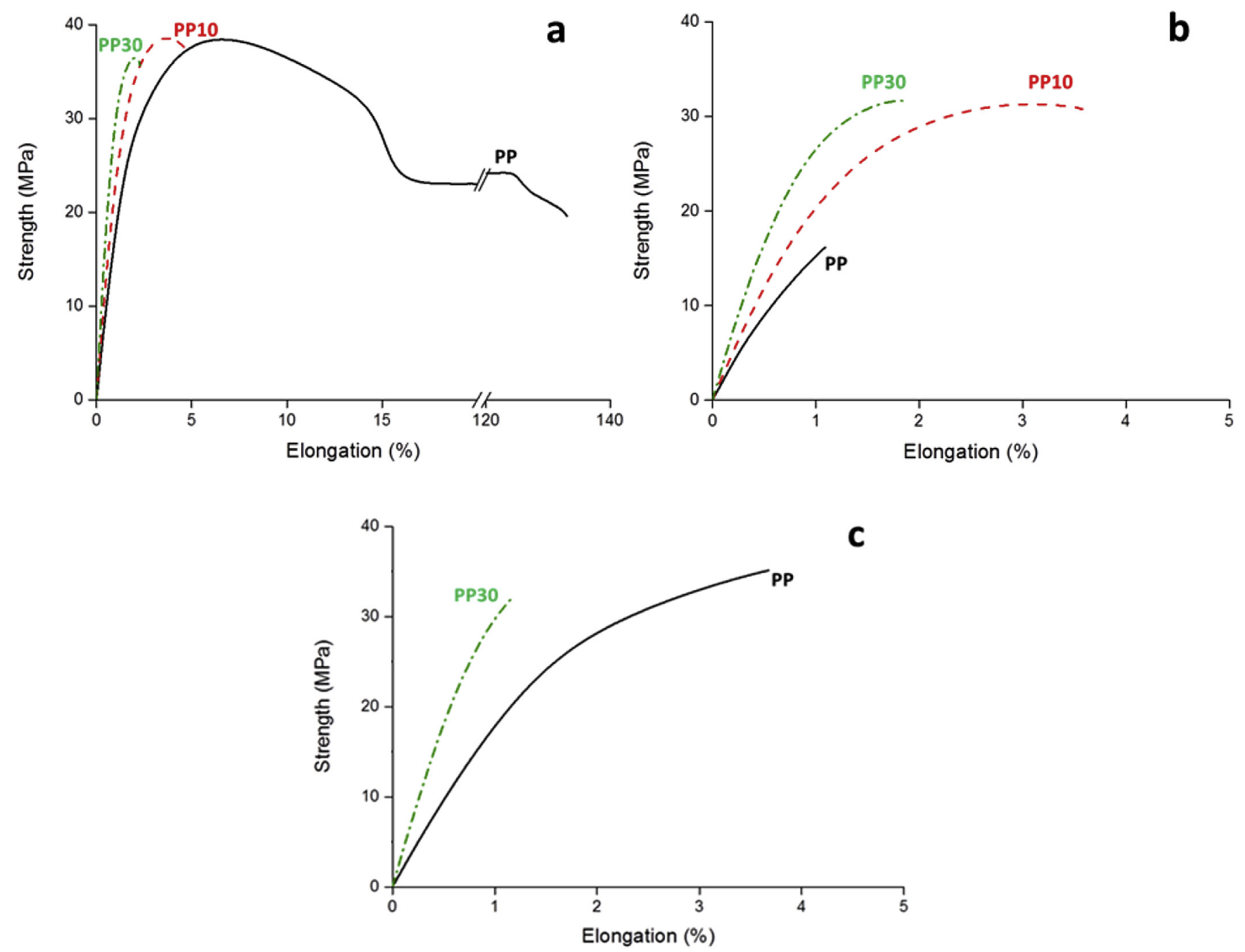

Fig. 2. Tensile curves at the initial (a), naturally weathered (b) and artificially weathered (c) states of the studied materials.

Table 3

Tensile properties of PP and wood flour reinforced composites at the different weathered states.

\begin{tabular}{lllll}
\hline & $\begin{array}{l}\text { Young Modulus } \\
\text { E }(\mathrm{MPa})\end{array}$ & $\begin{array}{l}\text { Maximal strength } \\
\mathrm{RM}(\mathrm{MPa})\end{array}$ & $\begin{array}{l}\text { Elongation at max } \\
\text { strength ER }(\%)\end{array}$ \\
\hline UW & PP & $1668 \pm 140$ & $38.6 \pm 0.6$ & $6.7 \pm 0.1$ \\
& PP10 & $2680 \pm 76$ & $38.6 \pm 0.2$ & $3.7 \pm 0.0$ \\
& PP30 & $4211 \pm 62$ & $36.5 \pm 0.4$ & $2.0 \pm 0.1$ \\
NW & PP & $1878 \pm 45$ & $15.4 \pm 2.9$ & $1.0 \pm 0.2$ \\
& PP10 & $2492 \pm 11$ & $31.8 \pm 0.40$ & $3.1 \pm 0.1$ \\
& PP30 & $3525 \pm 41$ & $31.5 \pm 0.3$ & $1.8 \pm 0.1$ \\
AW & PP & $1930 \pm 20$ & $39.2 \pm 0.5$ & $3.6 \pm 0.1$ \\
& PP30 & $4210 \pm 50$ & $34.6 \pm 0.3$ & $0.9 \pm 0.1$ \\
\hline
\end{tabular}

Table 4

$\Delta \mathrm{L}^{*}, \Delta \mathrm{a}^{*}$ and $\Delta \mathrm{b}^{*}$ variations between unaged and natural and artificial weathered samples.

\begin{tabular}{lllllll}
\hline & NW & & & & & AW \\
& PP & PP10 & PP30 & & PP & PP30 \\
\hline$\Delta \mathrm{L}^{*}$ & -0.64 & 7.23 & 25.31 & & 0.37 & 20.21 \\
$\Delta \mathrm{a}^{*}$ & 0.16 & -2.35 & -8.56 & & 0.01 & -8.21 \\
$\Delta \mathrm{b}^{*}$ & 0.24 & -8.12 & -14.81 & & 0.16 & -13.31 \\
\hline
\end{tabular}

oxidation of lignin leads to the formation of water soluble products which can be lixiviated by rainfalls. As concerns $\Delta \mathrm{a}^{*}$ and $\Delta \mathrm{b}^{*}$, a decrease is observed which is also more intense as the wood content increases. The photo-mechanism explaining those variations has already been established by Muasher et al. and proposes that the paraquinonic structures present in lignin undergo reduction to hydroquinonic molecules under UV rays which results in a decrease of yellowness and corresponds to a decrease of $b^{*}$ [12]. The decrease of $a^{*}$ is also linked to the degradation of lignin. Moreover the evolution of the three coordinates is higher for the natural weathering compared to artificial one which corroborates mechanical properties evolution. This last point will be largely discussed in section 2.4 .

\subsubsection{Gloss}

The repartition of the intensity of light reflected by the composite at different angles from 10 to $-70^{\circ}$ is represented in Fig. 3 . The higher light intensity is recorded for the specular angle meaning the angle opposed at the angle of incidence relative to the normal of the sample.

As concerned unaged samples, the specular peak for virgin PP is higher than those of biocomposites meaning that the surface is glosser and smoother since gloss is related to the amount of light 
scattered around the specular direction [20]. By comparison between PP10 and PP30, the specular peak for the highest loading is lower. This observation can be due to a higher fraction of wood particles located at the surface which induces roughness and therefore a gloss loss.

After natural weathering, the specular peak of NWPP becomes wider extended on several angles and more than six times less intense than non-weathered PP. Thus the natural weathering has caused changes on the gloss aspect. Also the plots corresponding to NWPP10 and NWPP30 do not have the same aspect as nonweathered composites. The reflection is no more specular but diffuse since the materials reflection is distributed in all the directions, especially for the NWPP30 composite. Moreover the peaks are less intense than the peak obtained after analysis of neat PP so the weathering was more impactful. Furthermore the specular peak
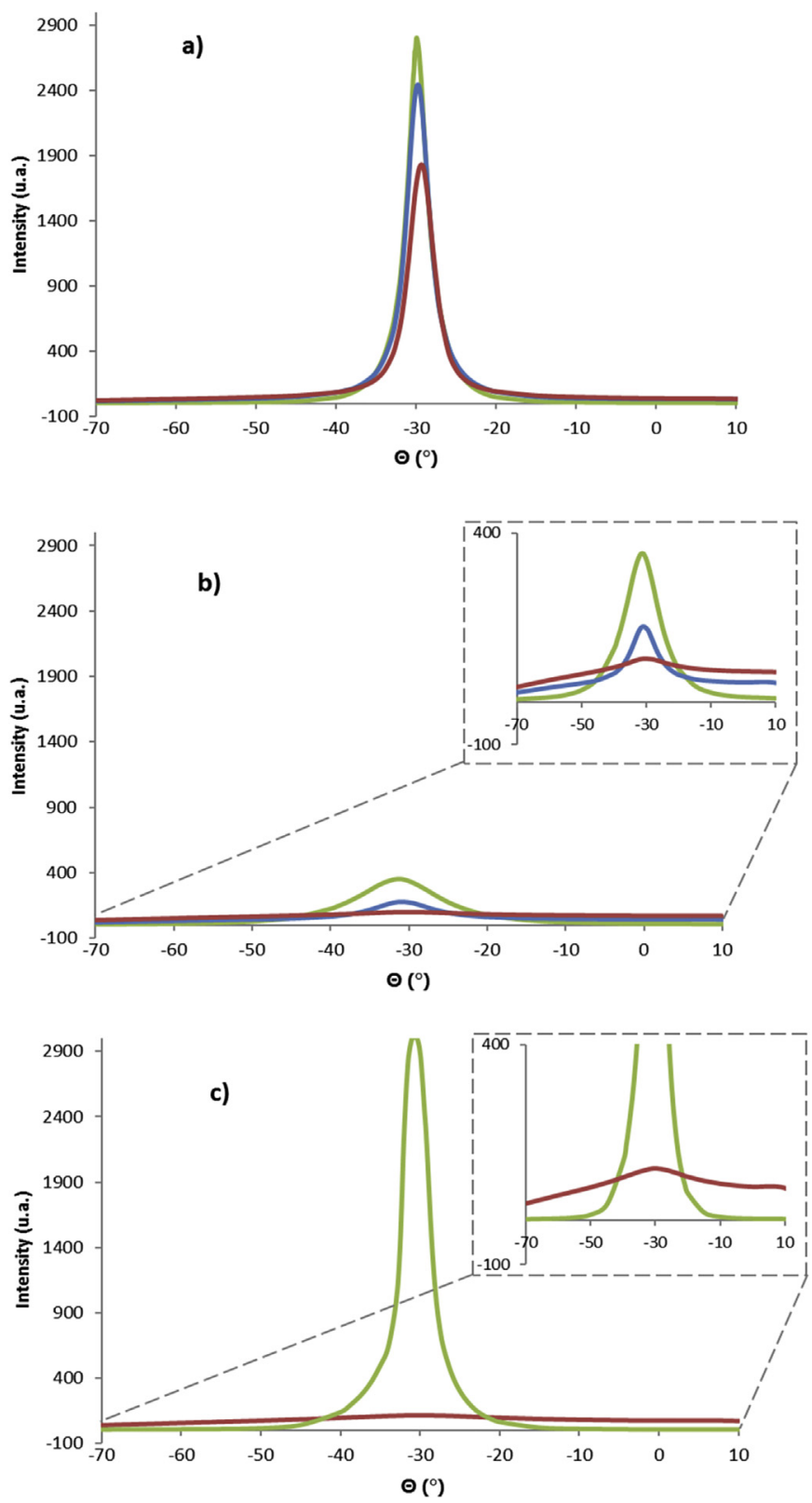

Fig. 3. Angular repartition of light reflected by non-weathered (a), naturally (b) and artificially weathered (c) neat PP (green), PP10 (blue) and PP30 (red). (For interpretation of the references to colour in this figure legend, the reader is referred to the web version of this article.) is barely visible for NWPP30 and less defined than for NWPP10. It suggests that increasing the wood flour loading from 10 to $30 \mathrm{wt} \%$ results in a loss of gloss which is caused by the deterioration of the surface. This suggestion will be confirmed by surface state characterizations (roughness).

Angular repartitions of the light reflected by artificially weathered PP and PP30 are also plotted in Fig. 4. A specular reflection is observed for AWPP which suggests that the gloss aspect has not been impacted by the accelerated conditions. Concerning AWPP30, the specular peak is barely visible and the incident light is reflected in several directions. This diffuse reflection leads to suppose that, as well as after the outdoor weathering, a surface state degradation has occurred. This observation has already been observed after accelerated weathering of WPC thanks to analyses by glossmeter [4]. Indeed non-weathered samples presented high gloss values which decrease for accelerated weathered samples. Also, roughness measurements will permit to verify the evolution of the surface state. However, the maximum value of reflected light intensity is slightly lower for artificially weathered than for naturally weathered PP30.

\subsection{Impact of weathering on surface topography}

\subsubsection{Surface microstructure}

Surfaces of the non-weathered, artificially and naturally weathered samples are observed by ESEM (Table 5). Neat UWPP shows a smooth surface whereas UWPP10 and UWPP30 present wood particles at the surface giving a rougher material. As concerns NWPP, surfaces micro-cracks are mainly highlighted which may be due to the degradation by chain scissions. The number and the depth of microcracks seem to increase with the flour loading, confirming that the presence of natural flour weakens the material under extreme conditions related to the natural weathering (heavy rain, sun and high humidity). AWPP shows a smooth surface with some impurities so the artificial weathering had not impact on surface of virgin PP. But AWPP30 presents a wood particle protrusion leading to a very rough surface. To conclude, it can be said that, a discrepancy may occur between a low ageing impact on biocomposites ultimate properties and a significant impact on visual changes. Therefore a thorough quantitative analysis of these changes is presented in the next part.

\subsubsection{Roughness}

Images of composites surface before and after natural and artificial weathering obtained by chromatic confocal imaging are shown in Fig. 6. The color of each point of the surface corresponds to an altitude whose scale is represented for each altitude image in the Figure. Each image has its own color scale so the images cannot be compared with each other by their colors. Values of Sa parameters are also given on Table 6.

Neat PP, PP10 and PP30 present relatively smooth surface before weathering. The average roughness increases with the wood loading (Sa between $1.68 \pm 0.49 \mu \mathrm{m}$ for PP and $3.82 \pm 1.17 \mu \mathrm{m}$ for PP30). It can be explained by an increase of the number of wood particles at the surface with the wood loading which induces irregularities, altitude variations and thus an increase of roughness. The low specular peak observed for PP30 by spectrogoniometric analysis is also explained by this increase of Sa.

The image corresponding to the surface analysis of natural weathered PP presents regular micro cracks and confirms the degradation of the polymer via molecular chain scission by photochemical reactions under ultraviolet weathering [21]. The profiles taken from composites exposed to natural weathering are not uniform and present some cavities of approximatively $800 \mu \mathrm{m}$. These cavities are certainly the imprint of wood particles which 

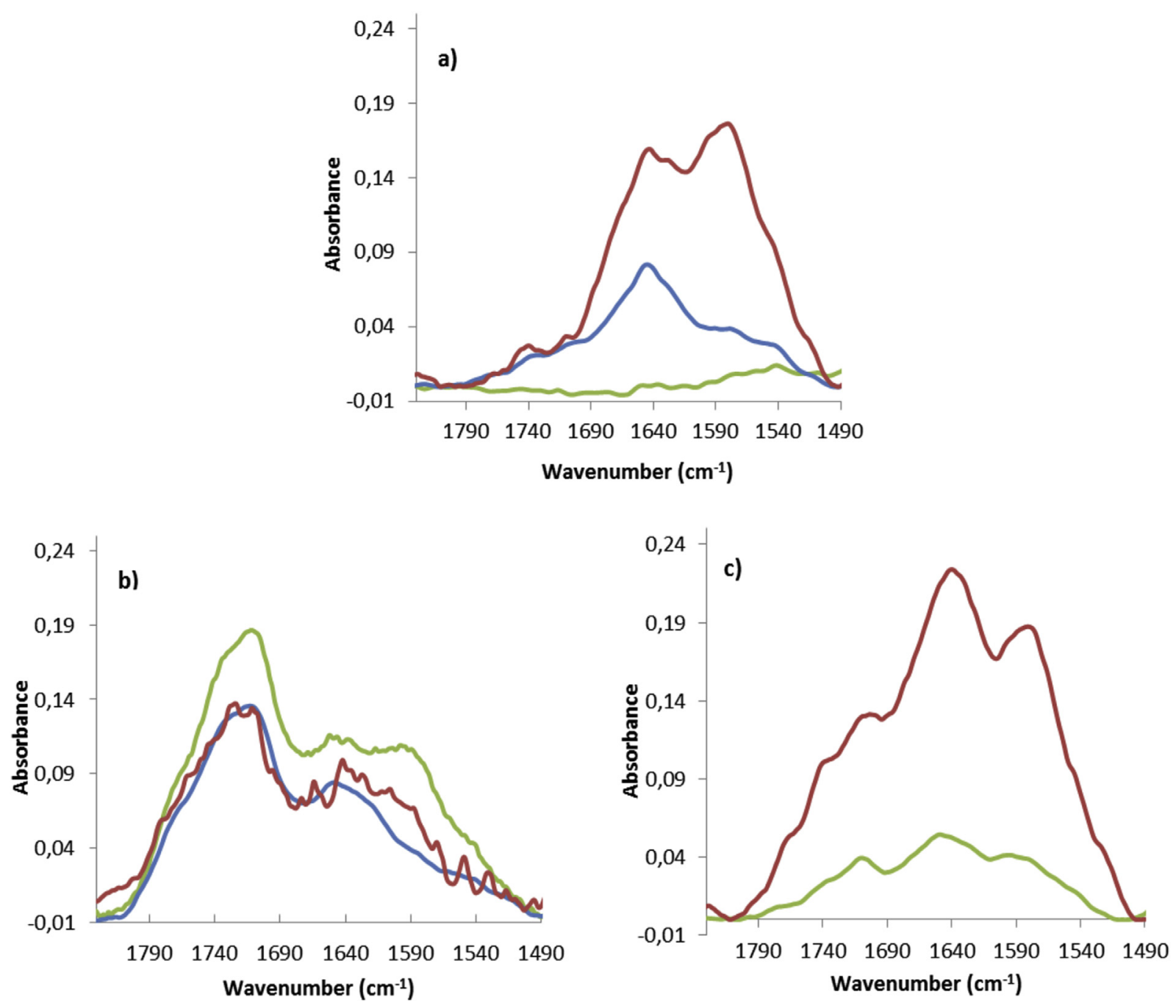

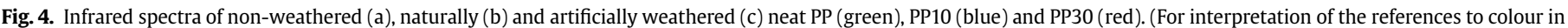
this figure legend, the reader is referred to the web version of this article.)

have been removed from the surface under rain. These results are in accordance with the Sa parameter which increases after natural weathering for all composites because of the presence of these gaps. Also the PP matrix can play a role on the changes of the composites surface states since it can undergo degradation [21]. Furthermore, the number of cavities on the altitude profile and the increase of the roughness parameter are stronger for NWPP30. It is due to a higher quantity of wood particles on surface which were removed during the weathering provoking higher altitude variations.

As it can be seen on the altitude profiles taken for AWPP, the polymer has not been damaged by the artificial weathering. However, little fractures are present on the surface of AWPP30 composite: the composite was degraded by the accelerated conditions. But as already concluded after color measurements and mechanical tests, the artificial weathering has less harmful impact on the surface state of materials even if it causes a rougher surface than nonweathered composites with some microcracks (which have been seen on SEM images) and an increase of the Sa parameter. The emergence of these little fractures seems to be the result of the degradation of the PP matrix but also of the weakened adhesion between the matrix and the wood particles due to accelerated conditions. Indeed gaps are formed on the surface of AW PP30 at the interface matrix/wood particle despite the presence of coupling agent. The Sa parameter of the PP polymer did not significantly change compared to UWPP. Nevertheless, the roughness parameter of AWPP30 increases after the artificial ageing and this evolution is in accordance with the altitude profile. Thus these results allow confirming the hypothesis given after spectrogoniometric analysis.

\subsection{Impact of weathering on microstructure}

\subsubsection{Molecular weight}

Unweathered WPC exhibit close molecular weights in number Mn and in weight Mw and close polydispersity indexes (Table 7). Otherwise Mn and Mw are higher than neat PP ones. A same trend was observed in a previous study [22]. Indeed, this increase can be due to the formation of bonds between wood flour components and polymer chains favored by high temperatures conditions during injection molding.

As concerns naturally weathered materials, $\mathrm{Mn}$ and $\mathrm{Mw}$ decrease for PP and WPC because of chain scission phenomenon caused by thermo- and photo-oxidative degradations. However, polymer chains of virgin PP underwent stronger scissions: The 
Table 5

ESEM photographs of PP and wood flour reinforced composites at the different weathered states.



presence of wood flour seems to stabilize the polymer against chain scissions. Indeed, by comparison with mechanical properties, the Young's modulus did not increase for WPC after natural weathering contrary to neat PP. Thus crystallization demonstrated by this stiffness increase and molecular weight decrease was favored for virgin polymer [19].

Less significant changes in Mn and Mw are noted after artificial weathering of PP and WPC.

\subsubsection{Chemical characteristics}

The absorption band associated to $\mathrm{C}=\mathrm{O}$ bond vibration is followed during the weathering stage since carbonyl groups formation can demonstrate an oxidative degradation (Fig. 4). For this, the absorbance at $1715 \mathrm{~cm}^{-1}$ is noted in Table 8 .

Firstly, an absorbance increase with the wood loading is observed at $1715 \mathrm{~cm}^{-1}$ for non-weathered samples. Indeed components present in wood flour include $\mathrm{C}=\mathrm{O}$ functional groups inducing a maximal absorbance higher than zero for WPC spectra contrary to PP [10], [23]. Otherwise, the increase of carbonyl concentration after natural weathering implies degradation by oxidation process. A more drastic increase is noted for naturally weathered PP. The observation confirms SEC results suggesting that
PP experienced stronger chain scissions. The PCA approach will permit to verify these relationships.

As well as for all previous characteristics, the artificial weathering caused less change in absorbance values especially for neat PP.

\subsection{Similarities and correlations}

In this section, all the characteristics of PP and WPC are resumed in order to understand similarities and differences between samples and establish relationships between mechanical, physical and microstructural properties.

\subsubsection{Study of samples (individuals)}

The study of samples made by PCA is presented in the Fig. 5 . Here, the two orthogonal axes explain about $80 \%$ of total information.

The factorial plan giving the samples' projection clearly highlights the differences between samples from different wood loading since three groups can be formed according to the wood rate. So the second component of the PCA mainly explains a contrast between neat PP, PP10 and PP30. These results reveal the major impact of the wood flour loading on the materials. 
Table 6

Altitude profiles and roughness parameters Sa $(\mu \mathrm{m})$ of PP and wood flour reinforced composites at the different states.

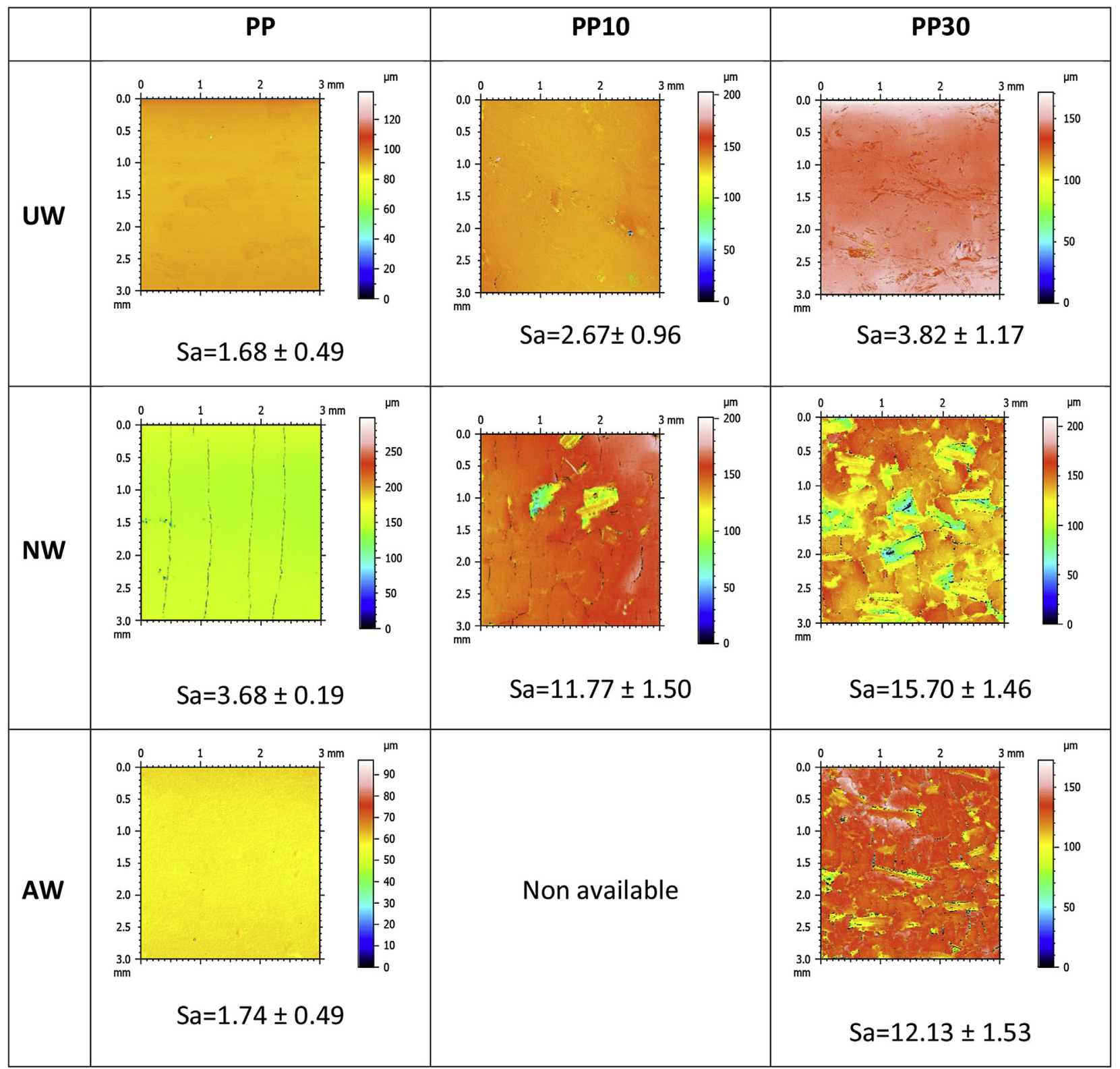

Otherwise, in regards of the relative positions of samples according to the first principal axis which contains the most important information, the type of weathering seems to have an

Table 7

Molecular weights in number (Mn) and in weight (Mw) and polydispersity indexes (Ip) of non-weathered, artificially and naturally weathered samples (N.A. = Non Applicable).

\begin{tabular}{lllll}
\hline & & $\mathrm{Mn}\left(\mathrm{g} \cdot \mathrm{mol}^{-1}\right)$ & $\mathrm{Mw}\left(\mathrm{g} \cdot \mathrm{mol}^{-1}\right)$ & $\mathrm{Ip}$ \\
\hline \multirow{2}{*}{ UW } & PP & $41025 \pm$ N.A. & $253554 \pm$ N.A. & 3.4 \\
& PP10 & $69640 \pm 2970$ & $294095 \pm 32067$ & 4.2 \\
& PP30 & $55070 \pm 2249$ & $281055 \pm 24204$ & 5.1 \\
NW & PP & $6703 \pm$ N.A. & $30264 \pm$ N.A. & 4.5 \\
& PP10 & $25185 \pm 233$ & $178535 \pm 6385$ & 7.1 \\
& PP30 & $31025 \pm 8987$ & $259490 \pm 17918$ & 8.8 \\
\multirow{4}{*}{ AW } & PP & $6703 \pm$ N.A. & $264313 \pm$ N.A. & 4.4 \\
& PP30 & $40647 \pm$ N.A. & $370752 \pm$ N.A. & 9.1 \\
\hline
\end{tabular}

influence on the WPC properties. Indeed, UW samples present high values on the first component whereas NW samples exhibit lower values with intermediate values for AW samples whatever the wood loading. So the first principal component represents the state of samples.

\subsubsection{Study of properties (variables)}

The correlation circle (Fig. 6) allows explaining the position of samples after projection on a plan and verifying the correlations between properties. The centered-reduced dataset is used for the correlation circle representation.

The correlation circle is represented in Fig. 6. The modulus E is well represented by the second component since its vector is very close to this axis. It means that the discrimination between samples according to the second component, so here according to the wood loading (Fig. 4), is mainly made by the modulus. Similarly, the 
Table 8

Absorbance at $1715 \mathrm{~cm}^{-1}$ for non-weathered, artificially and naturally weathered samples.

\begin{tabular}{lll}
\hline & & Maximal absorbance at $1715 \mathrm{~cm}^{-1}$ \\
\hline UW & PP & 0 \\
& PP10 & 0.01 \\
NW & PP30 & 0.03 \\
& PP & 0.19 \\
& PP10 & 0.13 \\
AW & PP30 & 0.13 \\
& PP & 0.04 \\
& PP30 & 0.13 \\
\hline
\end{tabular}

maximal absorbance $\mathrm{A}$ corresponding to $\mathrm{C}=\mathrm{O}$ bond vibration and the molecular weight in number Mn have a strong contribution to the first component. So A and Mn mostly explain the discrimination between samples from the different states (UW, NW and AW). When A increases, Mn proportionally decreases. It is explained by the fact that smaller chains (Mn decrease) obtained by chain scissions are caused by oxidation process (absorbance at $1715 \mathrm{~cm}^{-1}$ increase).

We can see that $\mathrm{L}^{*}$ and Sa both display close correlation coefficients with the two components so they are extremely correlated. Indeed, WPC become lighter and rougher ( $\mathrm{L}^{*}$ and Sa increase) with the weathering. Also, even if a small angle is calculated between Mw and $\mathrm{a}^{*}$, any correlation can be highlighted since Mw is a parameter specific to the matrix whereas the variation in color is given by the wood flour. The positive correlation raised between $G$ and ER suggests that the elongation at yield is linked to the surface state of samples since surface state directly impacts glossy aspect. Indeed the microcracks and hollows appearing on the surface during the weathering can probably play a role in the decrease of the elongation properties.

Otherwise, Sa and ER are negatively correlated since they are opposed to each other according to the gravity center. This indicates that ER proportionally decreases with the increase of Sa and confirms the previous hypothesis concerning the link between elongation at yield and topography. However, in view of maximal strength RM coordinates compared to the other properties ones,

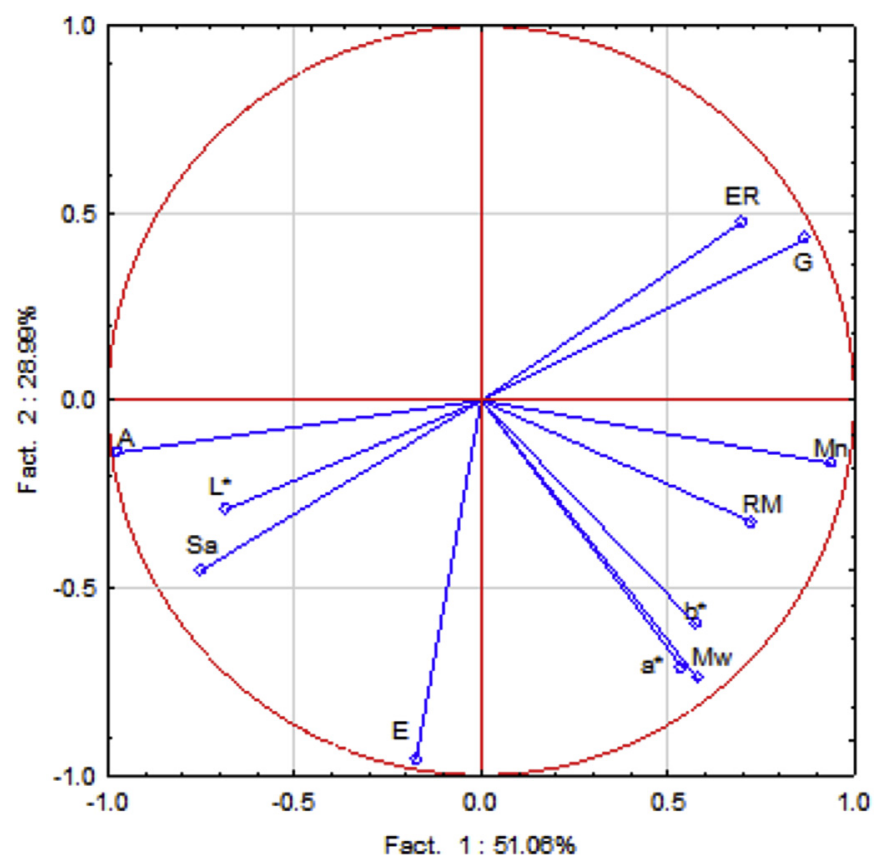

Fig. 6. Correlation circle of properties (active variables used for the calculations of the components).

any correlation can be done with this mechanical property since angles formed with other properties are too high.

\section{Conclusion}

The aim of this study was to understand the effects of two types of weathering on the mechanical properties, the visual aspect, the surface topography and the microstructure of PP and wood flour reinforced PP composites at 10 and $30 \mathrm{wt} \%$.

Spectrocolorimetric measurements of biocomposites allowed reporting that $\mathrm{L}^{*}$ increased and $\mathrm{b}^{*}$ decreased after both weathering.



Fig. 5. Projection of samples on a factorial plan. 
It means that the initial brown color given by the wood flour which is more pronounced for the highest content of wood disappeared in favor of a surface bleaching. This discoloration is due to the transformation of the chromophoric structures present in lignin into hydroquinonic structures because of a photodegradation mechanism. Spectrogoniometric analyses and roughness measurements showed that the surface state of the composites is affected during the two weathering. The images taken by SEM permit to confirm this ageing effect. The microstructure also evaluated after weathering confirmed the degradation of the polymer chains.

Mechanical properties were more affected by the natural weathering than by the artificial one. Also, the artificial weathering resulted in lower visual aspect, mechanical performance, surface state and microstructure changes. But the acceleration factor for the artificial weathering should be increased in order to simulate a one year-natural weathering in order to compare easier the effects of the two types of weathering on the materials properties.

The PCA showed that the flour loading had a great impact on the materials since the main first component explained by the Young's modulus discriminates the different flour loading. The differences noted between the different states, and thus according to the second axis, are mainly explained by the microstructure.

Also, the positive relation between elongation at yield and gloss and the anti-correlation noted between topography and this same mechanical property suggest that elongation properties are correlated to the surface state: the rougher the surface, the more affected the elongation at maximal strength. Another anti-correlation is noted between $\mathrm{Mn}$ and $\mathrm{A}$ and is explained by the chain scission phenomenon.

\section{Acknowledgements}

This research did not receive any specific grant from funding agencies in the public, commercial, or not-for-profit sectors.

\section{References}

[1] Nova Institut, Feature Wind Energy, JEC Compos. Mag. (2015) 18-19.

[2] A.Q. Nyrud, A. Roos, M. Rødbotten, Product attributes affecting consumer preference for residential deck materials, Can. J. For. Res. 38 (2008) 1385-1396, http://dx.doi.org/10.1139/X07-188.

[3] F.P. La Mantia, M. Morreale, Accelerated weathering of polypropylene/wood flour composites, Polym. Degrad. Stab. 93 (2008) 1252-1258, http:// dx.doi.org/10.1016/j.polymdegradstab.2008.04.006.

[4] Y. Peng, R. Liu, J. Cao, Y. Chen, Effects of UV weathering on surface properties of polypropylene composites reinforced with wood flour, lignin, and cellulose, Appl. Surf. Sci. 317 (2014) 385-392, http://dx.doi.org/10.1016/ j.apsusc.2014.08.140.

[5] L. Soccalingame, D. Perrin, J.-C. Bénézet, S. Mani, F. Coiffier, E. Richaud, A. Bergeret, Reprocessing of artificial UV-weathered wood flour reinforced polypropylene composites, Polym. Degrad. Stab. 120 (2015) 313-327, http:// dx.doi.org/10.1016/j.polymdegradstab.2015.07.013.
[6] Y. Peng, R. Liu, J. Cao, Characterization of surface chemistry and crystallization behaviour of polypropylene composites reinforced with wood flour, cellulose and lignin during accelerated weathering, Appl. Surf. Sci. (2015), http:// dx.doi.org/10.1016/j.apsusc.2015.01.147.

[7] P. Filson, B.E. Dawson-Andoh, L. Matuana, Colorimetric and vibrational spectroscopic characterization of weathered surfaces of wood and rigid polyvinyl chloride-wood flour composite lumber, Wood Sci. Technol. 43 (2009) 669-678, http://dx.doi.org/10.1007/s00226-009-0254-5.

[8] T.-H. Yang, T.-H. Yang, W.-C. Chao, S.-Y. Leu, Characterization of the property changes of extruded wood-plastic composites during year round subtropical weathering, Constr. Build. Mater 88 (2015) 159-168, http://dx.doi.org/ 10.1016/j.conbuildmat.2015.04.019.

[9] M. Kiguchi, Y. Kataoka, H. Matsunaga, K. Yamamoto, P.D. Evans, Surface deterioration of wood-flour polypropylene composites by weathering trials J. Wood Sci. 53 (2006) 234-238, http://dx.doi.org/10.1007/s10086-0060838-8.

[10] S. Butylina, M. Hyvärinen, T. Kärki, A study of surface changes of woodpolypropylene composites as the result of exterior weathering, Polym. Degrad. Stab. 97 (2012) 337-345, http://dx.doi.org/10.1016 j.polymdegradstab.2011.12.014.

[11] X. Zhou, S. Huang, L. Chen, Effect of antiaging agents on the outdoor natura weathering of bamboo powder/polypropylene foamed composites, J. Viny Addit. Technol. (2014), http://dx.doi.org/10.1002/vnl.21433 n/a-n/a.

[12] M. Muasher, M. Sain, The efficacy of photostabilizers on the color change of wood filled plastic composites, Polym. Degrad. Stab. 91 (2006) 1156-1165, http://dx.doi.org/10.1016/j.polymdegradstab.2005.06.024.

[13] J.S. Fabiyi, A.G. McDonald, M.P. Wolcott, P.R. Griffiths, Wood plastic composites weathering: visual appearance and chemical changes, Polym. Degrad. Stab. 93 (2008) 1405-1414, http://dx.doi.org/10.1016 j.polymdegradstab.2008.05.024.

[14] C. Homkhiew, T. Ratanawilai, W. Thongruang, Effects of natural weathering on the properties of recycled polypropylene composites reinforced with rubberwood flour, Ind. Crops Prod. 56 (2014) 52-59, http://dx.doi.org/10.1016/ j.indcrop.2014.02.034.

[15] M.I. Popa, S. Pernevan, C. Sirghie, I. Spiridon, D. Chambre, D.M. Copolovici, N. Popa, Mechanical properties and weathering behavior of polypropylenehemp shives composites, J. Chem. 2013 (2013) 1-8, http://dx.doi.org/ $10.1155 / 2013 / 343068$

[16] A. Naumann, I. Stephan, M. Noll, Material resistance of weathered woodplastic composites against fungal decay, Int. Biodeterior. Biodegr. 75 (2012) 28-35, http://dx.doi.org/10.1016/j.ibiod.2012.08.004.

[17] K.B. Adhikary, S. Pang, M.P. Staiger, Accelerated ultraviolet weathering of recycled polypropylene-sawdust composites, J. Thermoplast. Compos. Mater 22 (2009) 661-679, http://dx.doi.org/10.1177/0892705709096550.

[18] STIL, Optical Principles 1: Confocal Chromatic, 2016, pp. 38-40. http://www stilsa.com/EN/pdf/optical principles CCS.pdf.

[19] B. Fayolle, E. Richaud, J. Verdu, F. Farcas, Embrittlement of polypropylene fibre during thermal oxidation, J. Mater. Sci. 43 (2007) 1026-1032, http:/ dx.doi.org/10.1007/s10853-007-2242-1.

[20] R. Alexander-Katz, R.G. Barrera, Surface correlation effects on gloss, J. Polym. Sci. 36 (1997) 1321-1334.

[21] N.M. Stark, L.M. Matuana, Ultraviolet weathering of photostabilized woodflour-filled high-density polyethylene composites, J. Appl. Polym. Sci. 90 (2003) 2609-2617, http://dx.doi.org/10.1002/app.12886.

[22] L. Soccalingame, A. Bourmaud, D. Perrin, J-C. Bénézet, A. Bergeret, Reprocessing of wood flour reinforced polypropylene composites: impact of particle size and coupling agent on composite and particle properties, Polym. Degrad. Stab. 113 (2015) 72-85, http://dx.doi.org/10.1016/ j.polymdegradstab.2015.01.020.

[23] J. Li, H.-C. Hu, X.-S. Chai, Rapid method for determination of carbonyl groups in lignin compounds by headspace gas chromatography, J. Chromatogr. A 1404 (2015) 39-43, http://dx.doi.org/10.1016/j.chroma.2015.05.055. 